\title{
Correction to: Characteristics of residual lymph nodes after six months of antituberculous therapy in HIV-negative individuals with cervical tuberculous lymphadenitis
}

Hyeri Seok', Ji Hoon Jeon', Kyung Ho Oh³, Hee Kyoung Choi ', Won Suk Choi ${ }^{1}$, Young Hen Lee ${ }^{2}$, Hyung Suk Seo ${ }^{2}$, Soon Young Kwon ${ }^{3}$ and Dae Won Park ${ }^{1 *}$

Correction to: BMC Infect Dis (2019) 19:867 https://doi.org/10.1186/s12879-019-4507-0

After publication of the original article [1], we were notified that an author's name has been incorrectly spelled. Soon You Kwon's correct full name is Soon Young Kwon.

The original article has been corrected.

\begin{abstract}
Author details
${ }^{1}$ Division of Infectious Diseases, Department of Medicine, Korea University Ansan Hospital, Korea University Medicine, 123 Jeukgeum-ro, Danwon-gu, Ansan 15355, Republic of Korea. ${ }^{2}$ Department of Radiology, Korea University Ansan Hospital, Korea University Medicine, Ansan, Republic of Korea. ${ }^{3}$ Department of Otorhinolaryngology-Head and Neck Surgery, Korea University Ansan Hospital, Korea University Medicine, Ansan, Republic of Korea.
\end{abstract}

Published online: 26 November 2019

\section{Reference}

1. Seok H, et al. Characteristics of residual lymph nodes after six months of antituberculous therapy in HIV-negative individuals with cervical tuberculous lymphadenitis. BMC Infect Dis. 2019;19:867. https://doi.org/10. 1186/s12879-019-4507-0.

* Correspondence: pugae1@korea.ac.kr

${ }^{1}$ Division of Infectious Diseases, Department of Medicine, Korea University Ansan Hospital, Korea University Medicine, 123 Jeukgeum-ro, Danwon-gu, Ansan 15355, Republic of Korea

Full list of author information is available at the end of the article

(c) The Author(s). 2019 Open Access This article is distributed under the terms of the Creative Commons Attribution 4.0 International License (http://creativecommons.org/licenses/by/4.0/), which permits unrestricted use, distribution, and reproduction in any medium, provided you give appropriate credit to the original author(s) and the source, provide a link to the Creative Commons license, and indicate if changes were made. The Creative Commons Public Domain Dedication waiver (http://creativecommons.org/publicdomain/zero/1.0/) applies to the data made available in this article, unless otherwise stated. 